\title{
AN ELECTROMYOGRAPHIC STUDY OF MASTICATION IN THE RHESUS MONKEY (MACACA MULATTA)
}

\author{
J. A. MCNamara, JR. \\ Center for Human Growth and Development and Department of Anatomy, The University of Michigan, \\ Ann Arbor, MI 48104, U.S.A.
}

\begin{abstract}
Summary-Twenty-eight monkeys (Macaca mulatta) were monitored during 84 electromyographic recording sessions to study the function of certain masticatory and facial muscles during mastication. During the period of closing muscle function, strong activity was noted in the temporal and masseter musculature and in the superior head of the lateral pterygoid muscle. The relative participation of the elevator muscles differed among the four age groups. During the period of opening muscle activity, the suprahyoids and the inferior head of the lateral pterygoid muscle functioned during the depression of the lower jaw. A comparison of the results of this study with the numcrous human EMG studies of mastication indicate a basic similarity in muscle function during chewing in the two species, although age-related differences in specific muscle group activities do exist.
\end{abstract}

The process of mastication is a highly complex neuromuscular activity that relies upon feedback from articular. muscular. periodontal, lingual and other sensory receptors. In man, the functional activity of the orofacial musculature has been investigated in numerous electromyographic studies (e.g. Moyers, 1950; Carlsöö. 1952: Perry and Harris. 1954; Ahlgren. 1966: Moller, 1966). The purpose of this study is to determine the relative participation of certain masticatory and facial muscles of the rhesus monkey in mandibular movement associated with mastication.

Twenty-eight monkeys (Macaca mulatta) were used. To examine pattern differences associated with the age and maturational level of the animal, the monkeys were divided on the basis of dentitional development into four groups of seven. Group 1 (infants) was characterized by the presence of a complete deciduous dentition at the onset of the study. Group II (juveniles) had complete deciduous dentitions and the first permanent molars were erupting or were fully in occlusion. Group III (adolescents) had full permanent dentitions with the exception of unerupted third molars and partially erupted canines. Group IV (young adults) had complete permanent dentitions.

Masticatory sequences were monitored during 84 electromyographic recording sessions. Each animal was anaesthetized by intramuscular injection of 6$10 \mathrm{mg} / \mathrm{kg}$ of $\mathrm{Ketamine} \mathrm{HCl}$, a short-acting, dissociative anaesthetic which has only a minor and transient effect upon the neuromusculature (Kuroda and McNamara, 1972). The anaesthetized monkey was then placed in a soundproof chamber and seated in a primate restraining device especially designed for electromyographic procedures (McNamara, 1973a).
Electromyographic records were taken on Kodak Linagraph direct print paper using a Beckman Type R dynagraph amplifier and a Honeywell model 1108 visicorder. Bipolar platinum needle electrodes were inserted aseptically into the anterior and posterior portions of the temporal muscle, the anterior border of the superficial head of the masseter muscle, the orbicularis oris muscle, and in the suprahoid muscle group (anterior digastric, mylohyoid and geniohyoid muscles). Both heads of the lateral pterygoid were also monitored, using two $25 \mathrm{~mm}$, Teflon-insulated needle electrodes which were passed extra-orally through the sigmoid notch into one of the heads of the lateral pterygoid muscle. McNamara (1973b) and Grant (1973a) have suggested that the two heads of the lateral pterygoid are functionally independent. All recordings were taken from the musculature on the left side.

The location of electrode placement was examined in 12 animals after the final recording session. Drops of India ink were injected at the placement sites of the electrode tips (including those to the lateral pterygoid muscle), the animal sacrificed immediately, the areas examined by dissection, and the precise location of the electrodes within each muscle noted (McNamara, 1973b). Verification of electrode position at other recording sessions was based primarily on visual inspection. surface measurement, and muscular palpation.

The animal was isolated in a soundproof room for a minimum of thirty additional minutes to allow for complete anaesthetic recovery. Subsequently, the investigator entered the soundproof room and elicted masticatory sequences by feeding the animal small chunks of sugar and bits of apple. 
In the analysis of the EMG recordings of masticatory sequences, the chewing cycle was divided into opening and closing periods of muscle activity. The duration of the closing period was measured from the onset to the cessation of elevator activity. Although not studicd in detail, a "silent period" was observed in the initial stages of elevator muscle function: for the purpose of this study, the silent period was encompassed within the period of closing muscle activity. The period of opening muscle activity was defined as the time interval between two closing periods. Since no provision was made to monitur actual tooth conlact. the limits of the opening and closing periods described in this study were based upon electromyographic activity rather than actual jaw movements.

During the closing period of the chewing cycle, strong activity was noted in the temporal and masseter muscles and in the superior head of the lateral pterygoid (Fig. 1). The functional patterns of the temporal and masseter musculature differed among the age groups studied. In the infant monkeys (Group I), the anterior portion of the temporal muscle had the greatest activity of any of the monitored elevator muscles during the closing phase of chewing. In Group II, about half of the animals had anterior temporal dominance. The superficial head of the masseter and anterior temporal were cqual in the other half (Fig. la). In the older animals (Groups III and IV), the masseter muscle dominated the closing phase of mastication. The posterior temporal was active selectively during the beginning of the chewing sequence when the bolus was initially crushed (Fig. lb). Thus. in the older animals the masseter was the dominant muscle during mastication. and the posterior temporal fibres were recruited only when maximum chewing strength was needed.

No age-related differences in function were noted in the activity of the orbicularis oris and of the superior head of the lateral pterygoid muscle. The amplitude of the firings of these muscles varied greatly among animals of the same group and no intergroup differences could be identified.

During the period of opening muscle activity, the suprahyoids and the inferior head of the lateral pterygoid functioned as the lower jaw was depressed. The suprahyoids also demonstrated variable activity during the antagonistic phase of chewing. This activity during closing may have in part provided smoothness of movement and protection against injury.

The duration of the chewing cycle was also studied. For all animals in the study, the duration of the closing period of muscle activity averaged $200-300 \mathrm{msec}$ with a range of $150-500 \mathrm{msec}$. The opening phase was usually longer in duration, averaging $300-450 \mathrm{msec}$. The large variation observed in the duration of the chewing cycle within the same animal and among animals of the same age group made any maturation pattern difficult to identify.

A comparison of the results of the current study with those of the numerous human EMG studies (e.g.

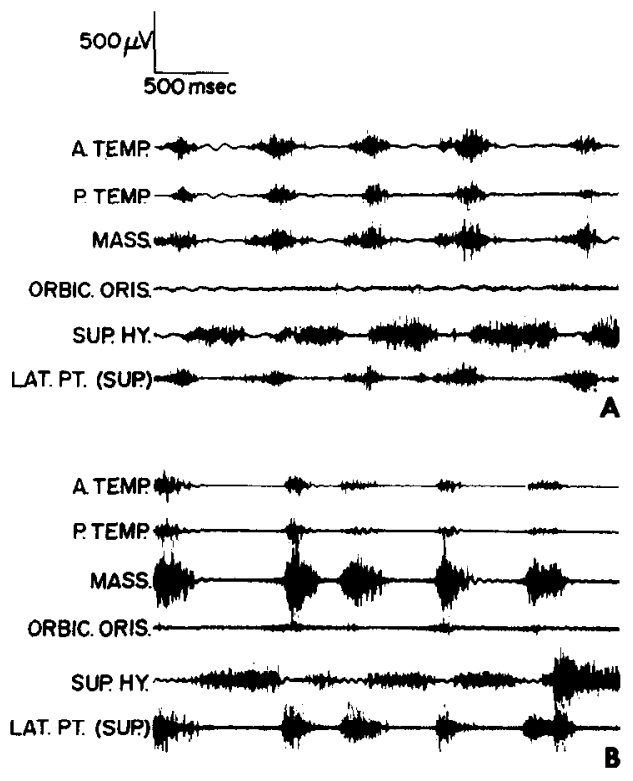

Fig. 1. Electromyographic recording of mastication in the rhesus monkey. (A) juvenile animal, (B) adult animal. Note the increased activity of the masseter muscle in the older group (recording speed $5 \mathrm{~mm} / \mathrm{sec}$ ).

Ahlgren, 1966; Møller, 1966) indicate that the patterns of electromyographic muscle activity during mastication are basically similar in man and $M$. mulatta. The temporal and masseter muscles of both species function primarily during the period of closing muscle activity while the suprahyoid muscle group, including the anterior digastric, mylohyoid, and geniohyoid muscles. are active during the opening period.

This study of the rhesus monkey also provided the investigator the opportunity of monitoring the function of the lateral pterygoid muscle during mastication. The function of this muscle is extremely difficult to study in man because of its location deep in the infratemporal fossa. In $M$. mulatta, the superior head is active only during the closing period of muscle activity while the inferior head participates primarily during the opening period. McNamara (1973b) has postulated that the two heads of the lateral pterygoid muscle are functionally independent. Contraction of the superior head positions and stabilizes the mandibular condyle and disk against the articular eminence of the temporal bone during closing movements of the mandible. In contrast, contraction of the inferior head moves the mandibular condyle downward and forward, a movement during which close approximation of the condylar head and disk to the articular eminence is not essential. The functional independence of the two heads of this muscle has also been demonstrated in a biomechanical analysis of the muscles of mastication in the rhesus monkey (Grant. 1973a). 
The results of the current study also indicate that in the rhesus monkey the relative participation of the muscles involved in closure during chewing appears to be related to the age and developmental level of the animal. In the youngest animals, the greatest electromyographic activity during mastication is observed in the anterior portion of the temporal muscle, with less activity in the posterior temporal and masseter muscles. As the animal matures, the role of the posterior portion of the temporal muscles decreases, while the role of the masseter muscle increases, eventually surpassing the level of activity of the anterior temporal muscle. Grant (1973b) has noted that the fibre orientation of the temporal muscle in Macaca mulatta is dependent upon the variables of age and sex. In young animals, the fibres of the posterior portion of the temporal muscle are arranged in such a way as to be effective jaw elevators, resembling the fibre orientation seen in man. However, with maturation, the posterior fibres become less and less suited for effective jaw closure. In the adult animal, and especially in the male adult, the posterior fibres serve primarily as retractors and stabilizers of the lower jaw and the participation in closure of the mandible during mastication is reduced.

The results of the current study indicate that there is a basic similarity between the electromyographic masticatory patterns recorded for the rhesus monkey and for man although age-related differences in specific muscle group activities do exist.

Acknowledgements - I acknowledge the technical assistance of M. C. McBride. The electromyographic facilities were provided by the Kresge Hearing Research Institute, University of Michigan.

\section{REFERENCES}

Ahlgren J. 1966. Mechanism of mastication. A quantitative cinematographic and electromyographic study of masticatory movements in children, with special reference to the occlusion of the teeth. Acta odont. scand. Suppl. 4424 , 13-183.

Carlsöö S. 1952. Nervous coordination and mechanical function of the mandibular elevators. Acta odont. scand. Suppl. 11 10, 122

Grant P. 1973a. Lateral pterygoid, two muscles? Am. J. Anat. 138, 1-10.

Grant P. 1973b. Biomechanical analysis of the masticatory apparatus of the rhesus macaque (primates; Macaca mulatta). Ph.D. Thesis, University of California, Berkeley, California.

Kuroda T. and McNamara J. A., Jr. 1972. The effect of ketamine and phencyclidine on muscle activity in nonhuman primates. Anesth. Analg. 51, 710-716.

McNamara J. A., Jr. 1973a. Restraint of monkeys for craniofacial research. J. dent. Res. 52, 183.

McNamara J. A.. Jr. 1973b. The independent functions of the two heads of the lateral pterygoid muscle. $A m$. J. Anat. 138, $197-206$.

Møller E. 1966. The chewing apparatus. An electromyographic study of the action of the muscles of mastication and its correlation to facial morphology. Acta physiol. scand. 69. 229 , suppl. 280.

Moyers R. E. 1950. An electromyographic analysis of certain muscles involved in temporomandibular movement. Am. J. Orthodont. 36, 481-515.

Perry H. T. and Harris S. C. 1954. Role of the neuromuscular system in functional activity of the mandible. $J . A m$. dent. Ass. 48, 665-673.

\begin{abstract}
Résumé-Vingt huit singes (Macaca mulatta) sont soumis à 84 sessions d'enregistrement électromyographique, pour étudier la fonction de certains muscles masticateurs et faciaux pendant la mastication. Pendant la période de fermeture buccale, une activité forte est notée dans la musculature temporale et massétérine, ainsi que dans le chef supérieur du muscle ptérygoidien latéral. La participation relative des muscles élévateurs est différente dans les quatre groupes d’âge. Pendant la période de l'activité musculaire, en cours d'ouverture, les muscles supra-hyoidiens et la partie inférieure du muscle ptérygoidien latéral fonctionnent pendant l'abaissement mandibulaire. Une comparaison des résultats de cette étude avec ceux des nombreuses études EMG humaines de mastication indique une similitude fondamentale en fonction musculaire pendant la mastication dans les deux espèces, bien qu'il existe des différences en rapport avec l'âge de l'activité de groupe musculaire spécifique.
\end{abstract}

Zusammenfassung - Bei 28 Affen (Macaca mulatta) wurden 84 elektromyographische Aufzeichnungen festgehalten, um die Funktion bestimmter Kau- und Gesichtsmuskeln während des Kauens zu untersuchen. Während der Funktion der Schließmuskeln wurde eine starke Aktivität in der temporalen und der Massetermuskulatur sowie in den oberen Kopfmuskeln und im M. pterygoideus lateralis festgestellt. Die relative Teilnahme der Öffnungsmuskeln unterschied sich bei den vier Altersgruppen. Während der Aktivität der Öffnungsmuskeln waren die suprahyoi dalen Muskeln, die unteren Kopfmuskeln und der M. pterygoideus lateralis beim Herabdrücken des Unterkiefers in Funktion. Ein Vergleich der Ergebnisse dieser Untersuchung mit zahlreichen menschlichen EMG-Untersuchungen beim Kauen zeigte eine grundlegende Ähnlichkeit der Muskelfunktion während des Kauens bei beiden Species, obwohl altersabhängige Unterschiede hinsichtlich der Aktivität spezifischer Muskelgruppen existierten. 